\title{
sciendo
}

\section{Prediction of Handball Players' Performance on the Basis of Kinanthropometric Variables, Conditioning Abilities, and Handball Skills}

\author{
by \\ Jose M. Saavedra ${ }^{1}$, Kristján Halldórsson ${ }^{1}$, Sveinn Porgeirsson ${ }^{1}$, Ingi P. Einarsson ${ }^{1}$, \\ Margrét L. Guðmundsdóttir ${ }^{1}$
}

\begin{abstract}
Handball (team handball) is a multifactorial sport. The aims of this study were (i) to analyse anthropometric variables, conditioning abilities, and handball skills in club handball players according to age and sex, and (ii) to develop multivariate models explaining club handball performance from a multidimensional perspective. Two hundred and twenty six handball players (age $16.9 \pm 4.0$ years, $54 \%$ males) participated in the study. The players belonged to under-14, under-16, under-19, and A teams. They were evaluated with a battery of 18 tests covering kinanthropometry, conditioning abilities, and handball skills. A one-way ANOVA with a Bonferroni post-hoc test was used to investigate differences between teams, and a t-test for differences between the sexes. For each team, a discriminant analysis was performed to determine differences between performance levels. The results showed little differences between the U19 and $A$ teams in any of the variables studied in either men or women, and that the lowest values corresponded to the U14 team. The differences according to sex were clear in the kinanthropometric and conditioning variables, but much less so in handball skills. The eight multivariate models that were constructed classified successfully from 48.5 to $100 \%$ of the sample using at most three variables (except for the women's A team whose model selected six variables). Conditioning variables were most discriminating in men, and handball skills in women. This would seem to reflect the different performance profiles.
\end{abstract}

Key words: power, endurance, speed, velocity, team sports games.

\section{Introduction}

Handball (team handball) is a multifactorial sport in which players jump, sprint, and change directions while performing several technical actions (throw, pass, block, etc.) to create favourable situations for scoring a goal. The many factors which influence handball include those of constitution-disposition, coordination (basic and specific), strength (basic and specific), endurance (basic and specific), nutrition, cognition, tactics, as well as social and external influences (Wagner et al., 2014). Modern handball has developed into a fast-paced, full body contact sport, with short high anaerobic bouts interspersed with aerobic actions (Michalsik, 2018). As a result of this evolution, variables related to constitutiondisposition (mainly anthropometric) and conditioning abilities (coordination, strength, endurance) have become determinants of handball performance. Indeed, $20 \%$ of sports science articles published on handball between 2013 and 2018 were on the "physical capacities and conditions" topic (Saavedra, 2018).

It is complicated to define performance in team sports because of the many criteria that could be applied. For example, many research studies have used the players' level - professional or semi-professional vs. amateur (Rivilla-García et al., 2010), elite vs top-elite (Ferragut et al., 2018), selected vs. non-selected for the national team

1 - Physical Activity, Physical Education, Sport and Health Research Centre, Sports Science Department, School of Social Sciences, Reykjavik University, Reykjavik, Iceland. 
(Zapartidis et al., 2009), the league played in, whether the first or the second division (Krüge et al., 2014), and team player status, whether a starter or a reserve (Saavedra et al., 2018). In this way, the differences that have been found in the kinanthropometric and conditioning variables depend on which performance criterion is selected. On the other hand, it is widely accepted that handball skills (specific coordination for Wagner et al., 2014) are important determinants of success in this sport (Gorostiaga et al., 2005; Rivilla-Garcia et al., 2011).

As the sport of handball has become more professional, the age at which maximal performance is reached has increased to around 27 years in men (Ghobadi et al., 2013) and 23 years in women (Weber and Wegner, 2016). Until adulthood, however, age still conditions players' kinanthropometric and conditioning abilities. Since there have only been two longitudinal studies of very young handball players (Lidor et al., 2005; Matthys et al., 2013), what happens before the age of 16 is not at all clear. For example, for both boys and girls, most conditioning variables improve between 12 and 13 years of age (Lidor et al., 2005). From the ages of 14 to 16 years, all conditioning abilities of male players improve except those of the sit-and-reach and shoulderrotation tests (Matthys et al., 2013). An earlier study by the same authors (Matthys et al., 2012), however, only found differences between male players of 14.00 to 14.49 years of age and those of 14.50 to 14.99 years of age in the 5-jump test and the $20 \mathrm{~m}$ sprint. In the same line, a study of U16 and U18 male players only found throwing speed differences in the standing throw and the jump throw (Ortega-Becerra et al., 2018). An earlier work comparing the same age groups (U16 and U18 players) found no differences in men, but differences in the squat jump (SJ) and $10 \mathrm{~m}$ and $20 \mathrm{~m}$ sprints in women (Ingebrigtsen et al., 2013). A study of elite women players found differences in the counter movement jump (CMJ) between U17 and U19 teams (Saavedra et al., 2018).

With regard to differences by sex, it would seem logical that they would exist in adulthood, and would directly influence the type of play performed by men and women. One study (Michalsik and Aagaard, 2015) revealed substantial gender-specific differences in match play, where female players covered more total distance and played at higher relative workloads than males. The men's game is characterized more by high intensity running and such actions as tackles received and performed (Michalsik and Aagaard, 2015). Not surprisingly, another recent study found that, compared with adult female players, male players were heavier, taller, faster, stronger, jumped higher, and had greater aerobic capacity, evaluated by general conditioning tests (Wagner et al., 2018). Another recent study (Pereira et al., 2018) conducted with the Brazilian national Olympic team found that men performed better than women in jumps (SJ, CMJ), sprints $(10$ and $20 \mathrm{~m}$ ), and agility (the zig-zag and Ttests); yet for younger handball players, differences by sex in anthropometric and conditioning variables do not seem at all clear. Thus, a study of conditioning abilities (Ingebrigtsen et al., 2013) only found better results in male than in female players (U16 and U18) in the SJ and sprints, while a study of younger players (14 years old) found differences between the sexes in body height and mass, a horizontal jump, a sit-and-reach test, and the number of abdominals performed in one minute abdominals (Dellagrana et al., 2010).

Although there have been studies of kinanthropometric variables, conditioning abilities, and playing skills in handball, few of them have analysed the dependence of these variables on age and sex or their relationship with performance. In this context therefore, the aims of the present study were to: (i) analyse anthropometric variables, conditioning abilities, and handball skills in club handball players in terms of age and sex, and (ii) develop a multivariate model explaining club handball performance from a multidimensional perspective.

\section{Methods}

\section{Participants}

Two hundred and twenty six handball players (54.0\% males), selected from best teams in Iceland, participated in the study. They were classified into the A teams $(n=29 ; 20.6 \pm 3.0$ years old; $65.5 \%$ males), under- 19 teams $(\mathrm{n}=35 ; 18.3 \pm$ 0.6 years old; $57.1 \%$ males), under- 16 teams $(\mathrm{n}=$ $73 ; 14.6 \pm 0.6$ years old, $43.8 \%$ males, ) and under14 teams ( $\mathrm{n}=89 ; 12.7 \pm 0.6$ years old; $49.4 \%$ males). The study was conducted during the 2017/18 
season, and was approved by the Ethics Committee of the Reykjavik University, respecting the principles of the Declaration of Helsinki.

\section{Measures}

All participants took a comprehensive battery of tests covering anthropometry, conditioning abilities, and specific handball skills. The anthropometric measurements were taken in accordance with the International Society for the Advancement of Kinanthropometry's standardized procedures (ISAK, 2011): stature, weight, arm span, hand length and width. The arm span index (arm span/height) and body mass index (BMI) were also calculated (Keys and Brozek, 1953). Measurements were made with a Seca model 769 stadiometer. The conditioning tests included the CMJ, medicine ball throw, hand dynamometry, $20 \mathrm{~m}$ sprint, T test, and yo-yo intermittent recovery level 2 test (yo-yo IR2). All these tests have been used in previous handball studies (Gorostiaga et al., 2005; Lidor et al., 2005; Matthys et al., 2013, 2012; Saavedra et al., 2018). Evaluation of the CMJ with hand on hips (Bosco et al., 1983) was done through measurements of high-speed video recordings (Casio, EX-F1, $300 \mathrm{fps}$, and $1920 \times 1080$ pixels) using the openlicence software package Kinovea (Kinovea 0.8.15 for Windows, available at http://www.kinovea.org). Once the jumps performed had been filmed, the jump time was calculated using Kinovea software, and the jump height $(\mathrm{cm})$ was estimated (Balsalobre-Fernández et al., 2014). The medicine ball (3 kg) throw with one knee on the floor (as adapted by Lidor et al., 2005) was scored as the distance reached (m). Hand dynamometry of the dominant hand (Council of Europe, 1988) was evaluated with a Vernier hand dynamometer (Vernier, Orlando, USA), with the participant seated and the elbow at $90^{\circ}$. The $20 \mathrm{~m}$ sprint (Lidor et al., 2005) was evaluated with photocells. The $\mathrm{T}$ test (adapted from Semenick, 1990) evaluated the change of direction and speed. The yo-yo IR2 test (Bangsbo et al., 2008; Krustrup et al., 2006) was scored as the speed $(\mathrm{km} / \mathrm{h})$. All except the hand dynamometry and yo-yo tests were conducted twice, recording only the better of the two scores for further analysis. The specific handball skills were evaluated: throwing speed at $7 \mathrm{~m}$ standing (Gorostiaga et al., 2005), $9 \mathrm{~m}$ after three steps (Gorostiaga et al., 2005), and $9 \mathrm{~m}$ after three steps and a jump (Vila et al., 2012). These three throws were evaluated with a radar gun (Sportradar 600, Warwick, UK), each being performed twice, recording only the better score in each case. Finally, a pass-to-wall test (Visnapuu and Jürimäe, 2008) was carried out. The line for the pass was drawn on the floor at $3 \mathrm{~m}$ from the wall. A $40 \times 40 \mathrm{~cm}$ square was drawn on the wall with the lower border $180 \mathrm{~cm}$ above the floor. Players stood behind the line in a comfortable catching or passing position and passed to the target on the wall at maximum speed for $30 \mathrm{~s}$. All the evaluations were completed in fifteen days (from November 25 to December 9) except for one group of players who were evaluated afterwards (January 22). The measurements were made during training. After the anthropometry measurements, participants performed a standardized warm-up procedure consisting of a stretching exercise, 4-6 repetitions of $30 \mathrm{~m}$ doing different exercises (knees up, lunge walk, etc.), 5-7 accelerations of $30 \mathrm{~m}$ building up the speed, and 10 minutes of passing. Full recovery was ensured between each of the trials.

Design and Procedures

The study was cross-sectional in nature. In the first part of the study, the independent variable was the age group (A team, U19, U16, and U14) and sex, and the dependent variables were anthropometric and conditioning variables and handball skills. In the second part of the study, the level of performance was evaluated relative to that of the starter players. In particular, each team was divided into two sub-groups (starters and non-starters) based on the coaches' evaluation. The choice of the six starter players was made by each (A team, U19, U16, and U14) of the teams' head coaches. While this choice could be considered to have a certain level of subjectivity, it is the usual mode of selection of starter players in team sports. Furthermore, this methodological approach is similar to that of previous studies (Lidor et al., 2005; Saavedra et al., 2018; Zapartidis et al., 2009). The study was approved by the Ethics Committee of the Reykjavik University respecting the principles of the Declaration of Helsinki.

\section{Statistical analysis}

All variables satisfied the tests of homoskedasticity (Levene's homogeneity test) and normality (Kolmogorov-Smirnov test). These 
analyses were performed for each sex. The basic descriptive statistics (mean and standard deviation) were calculated. A t-test was used to examine differences between sexes. The effect sizes of the differences were calculated (Cohen, 1988), interpreting them in accordance with the recommendations in the literature (Hopkins et al., 2009): $>0.1$ small, $>0.3$ moderate, $>0.5$ large, $>0.7$ very large, and $>0.9$ nearly perfect. A one-way ANOVA was used to examine differences between teams (A team, U18, U16, and U14). The Bonferroni post-hoc test was used to compare means. The eta-squared $\left(\eta^{2}\right)$ statistic, which describes the proportion of the variance attributable to a given factor, was calculated. A discriminant analysis was performed for each team and sex (eight models). Participants were classified by the sample-splitting method into two groups according to their performance level (starters and non-starters). The criterion used to determine whether a variable entered the model (i.e., discriminant function) was Wilks's lambda a measure of the deviations within each group with respect to the total deviations. The level of significance for all statistical tests was set at $p \leq$ 0.05 . All calculations were performed using SPSS version 20.0 .

\section{Results}

Table 1 presents the means and standard deviations of each anthropometric variable, and the results of the t-test (male vs. female) and the one-way ANOVA (age group). There were differences between male and female players in most variables (the exceptions being BMI and arm span index) except for U14, in which case there were only differences between the sexes in hand width. There were differences only between the A and U19 teams in the BMI (males) and the arm span index. U14 (male and female) scored the lowest in all variables.

Table 2 presents the means and standard deviations of each conditioning abilities, and the results of the t-test (male vs. female) as well as the one-way ANOVA (age group). In almost all the variables (the exception being the yo-yo IR2 test), there were differences between male and female players. There were differences only between the A and U19 teams in the medicine ball throw, the yo-yo IR2 test (males) and hand dynamometry (females). The U14 players scored the lowest in all variables.

Table 3 shows the means and standard deviations of each handball skills, and the results of the t-test (male vs. female) and the one-way ANOVA (age group). There were clear differences between the sexes in all teams (age groups) only in the $7 \mathrm{~m}$-standing and $9 \mathrm{~m}$-after-three-steps throwing speeds. There were no differences in any of the variables between the A and U19 teams. The U14 players scored the lowest in all variables.

Table 4 presents the results of the models of the discriminant analysis by performance (starters vs. non-starters) for each age group and sex. In men, the models correctly classified between 61.5 (U19 team) and $100 \%$ (U14 team) of the sample with at most three anthropometric, conditioning abilities, or handball skills. In women, the percentages that the models classified correctly ranged between 48.5 (U16 team) and 100\% (A team), with no more than three variables, mostly corresponding to handball skills, for all except the A team whose model selected six variables.

\section{Discussion}

The objective of this study was to analyse the anthropometric variables, conditioning abilities, and handball skills in handball players according to age and sex, and to develop a multivariate model explaining handball performance from a multidimensional perspective. In general, there were few differences between the A team and the U19 team in the variables studied in either men or women, and the U14 teams had the lowest values. While differences between male and female players were clear in the kinanthropometric and conditioning variables, this was less the case for handball skills. The eight multivariate models that were developed classified successfully from 48.5 to $100 \%$ of the samples with at most three variables (except for the A team female for which the model selected six variables). To the best of our knowledge, this has been the first study to analyse more than 200 players with such an extensive battery (18 in total) of tests, looking at the differences according to age and sex, and managing to predict handball performance with just a small number of variables. 


\section{Table 1}

Mean and standard deviation of each anthropometric variable. A t-test was used to compare means between sexes in each group, and a one-way analysis of variance (ANOVA) with Bonferroni post-hoc test was used to compare means between teams for each sex. Also given are the values of the effect sizes (ES) of the differences between the sexes (Cohen's d) and between teams (eta squared, $\eta^{2}$ )

\begin{tabular}{|c|c|c|c|c|c|c|c|}
\hline & $\begin{array}{l}\text { A Team } \\
(\mathrm{n}=29) \\
M \pm S D\end{array}$ & $\begin{array}{c}\mathrm{U} 19 \\
(\mathrm{n}=35) \\
\mathrm{M} \pm \mathrm{SD}\end{array}$ & $\begin{array}{c}\mathrm{U} 16 \\
(\mathrm{n}=73) \\
\mathrm{M} \pm \mathrm{SD}\end{array}$ & $\begin{array}{c}\mathrm{U} 14 \\
(\mathrm{n}=89) \\
\mathrm{M} \pm \mathrm{SD}\end{array}$ & $\mathrm{F}$ & $\eta^{2}$ & Differences \\
\hline \multicolumn{8}{|c|}{$\begin{array}{l}\text { Body height } \\
(\mathrm{cm})\end{array}$} \\
\hline Male & $183.88 \pm 5.13$ & $184.27 \pm 5.05$ & $177.77 \pm 8.22$ & $160.56 \pm 10.36$ & 55.1 & 0.62 & A,U19,U16>U14 \\
\hline Female & $172.20 \pm 5.65$ & $172.00 \pm 3.61$ & $167.57 \pm 5.15$ & $159.74 \pm 6.33$ & 24.1 & 0.54 & A,U19,U16> U14 \\
\hline ES & 2.16 & 2.80 & 1.49 & 0.10 & & & \\
\hline \multicolumn{8}{|c|}{$\begin{array}{l}\text { Body mass } \\
(\mathrm{kg})\end{array}$} \\
\hline Male & $86.89 \pm 11.03$ & $79.58 \pm 12.02$ & $71.31 \pm 14.32$ & $51.83 \pm 12.94$ & 41.1 & 0.57 & A,U19>U16>U14 \\
\hline Female & $73.73 \pm 8.41$ & $75.18 \pm 4.93$ & $64.04 \pm 9.32$ & $48.32 \pm 8.02$ & 37.7 & 0.63 & A,U19>U16>U14 \\
\hline t-test & 3.252 & 1.293 & 2.675 & 1.963 & & & \\
\hline ES & 1.34 & 0.48 & 0.60 & 0.33 & & & \\
\hline \multicolumn{8}{|l|}{$\begin{array}{l}\text { Arm span } \\
(\mathrm{m})\end{array}$} \\
\hline Male & $188.29 \pm 5.17$ & $188.88 \pm 9.23$ & $179.60 \pm 8.20$ & $159.91 \pm 12.45$ & 56.5 & 0.98 & A,U19>U16>U14; \\
\hline Female & $179.31 \pm 4.32$ & $176.64 \pm 5.05$ & $169.52 \pm 7.21$ & $158.50 \pm 7.26$ & 42.7 & 0.99 & $\begin{array}{c}\mathrm{A}>\mathrm{U} 16>\mathrm{U} 14 ; \\
\mathrm{U} 19>\mathrm{U} 14\end{array}$ \\
\hline t-test & 5.070 & 3.315 & 5.043 & 0.457 & & & \\
\hline ES & 2.09 & 1.65 & 1.31 & 0.14 & & & \\
\hline \multicolumn{8}{|c|}{ Hand 1. $(\mathrm{cm})$} \\
\hline Male & $19.95 \pm 0.70$ & $20.38 \pm 1.09$ & $19.77 \pm 0.79$ & $17.70 \pm 1.17$ & 45.6 & 0.57 & A,U19,U16>U14 \\
\hline Female & $18.86 \pm 0.60$ & $18.50 \pm 0.38$ & $18.40 \pm 0.80$ & $17.66 \pm 0.76$ & 13.7 & 0.37 & A,U19, U16>U14 \\
\hline t-test & 4.078 & 3.858 & 6.423 & $0.768(-0.04)$ & & & \\
\hline ES & 1.67 & 2.30 & 1.72 & -0.04 & & & \\
\hline \multicolumn{8}{|l|}{$\begin{array}{l}\text { Hand w. } \\
(\mathrm{cm})\end{array}$} \\
\hline Male & $11.89 \pm 0.45$ & $11.94 \pm 0.76$ & $11.56 \pm 0.62$ & $10.27 \pm 0.82$ & 39.4 & 0.54 & A,U19,U16>U14 \\
\hline Female & $10.46 \pm 0.37$ & $10.48 \pm 0.48$ & $10.52 \pm 0.49$ & $9.91 \pm 0.49$ & 12.1 & 0.28 & A,U19,U16>U14 \\
\hline t-test & 8.022 & 6.176 & 7.711 & 2.602 & & & \\
\hline ES & 3.47 & 2.31 & 1.86 & 0.53 & & & \\
\hline \multicolumn{8}{|c|}{ BMI $\left(\mathrm{kg} / \mathrm{m}^{2}\right)$} \\
\hline Male & $25.64 \pm 2.56$ & $23.46 \pm 3.56$ & $22.40 \pm 3.30$ & $19.96 \pm 3.71$ & 14.5 & 0.32 & $\mathrm{~A}>\mathrm{U} 19, \mathrm{U} 16>\mathrm{U} 14$ \\
\hline Female & $24.93 \pm 3.19$ & $26.05 \pm 9.38$ & $22.77 \pm 2.93$ & $18.87 \pm 2.54$ & 19.9 & 0.38 & A,U19,U16>U14 \\
\hline t-test & 0.736 & -1.415 & -0.054 & 1.762 & & & \\
\hline ES & 0.25 & -0.37 & -0.12 & 0.34 & & & \\
\hline \multicolumn{8}{|c|}{ Arm span i. } \\
\hline Male & $1.03 \pm 0.02$ & $1.02 \pm 0.03$ & $1.01 \pm 0.02$ & $0.99 \pm 0.03$ & 7.0 & 0.98 & $\mathrm{~A}>\mathrm{U} 19, \mathrm{U} 16>\mathrm{U} 14 ;$ \\
\hline Female & $1.04 \pm 0.02$ & $1.03 \pm 0.02$ & $1.01 \pm 0.03$ & $0.99 \pm 0.02$ & 17.1 & 0.99 & $\begin{array}{c}\mathrm{A}>\mathrm{U16}>\mathrm{U} 14 ; \\
\mathrm{U} 18>\mathrm{U} 14\end{array}$ \\
\hline t-test & 0.797 & -0.050 & -0.032 & -0.370 & & & \\
\hline ES & -0.50 & -0.39 & 0.01 & 0.01 & & & \\
\hline
\end{tabular}




\section{Table 2}

Mean and standard deviation of each physical fitness variable. A t-test was used to compare means between sexes in each group, and a one-way analysis of variance (ANOVA) with Bonferroni post-hoc test was used to compare means between teams for each sex. Also given are the values of the effect sizes (ES) of the differences between the sexes (Cohen's $d$ ) and between teams (eta squared, $\eta^{2}$ ) (male, $n=115$; female, $n=111$ ).

\begin{tabular}{|c|c|c|c|c|c|c|c|}
\hline & $\begin{array}{c}\text { A Team } \\
(\mathrm{n}=29) \\
\mathrm{M} \pm \mathrm{SD}\end{array}$ & $\begin{array}{c}\mathrm{U19} \\
(\mathrm{n}=35) \\
\mathrm{M} \pm \mathrm{SD}\end{array}$ & $\begin{array}{c}\mathrm{U} 16 \\
(\mathrm{n}=73) \\
\mathrm{M} \pm \mathrm{SD}\end{array}$ & $\begin{array}{c}\mathrm{U} 14 \\
(\mathrm{n}=89) \\
\mathrm{M} \pm \mathrm{SD}\end{array}$ & $\mathrm{F}$ & $\eta^{2}$ & Differences \\
\hline \multicolumn{8}{|l|}{$\mathrm{CMJ}(\mathrm{cm})$} \\
\hline Male & $48.46 \pm 5.14$ & $49.39 \pm 5.33$ & $40.18 \pm 8.26$ & $33.37 \pm 5.55$ & 34.2 & 0.54 & $\mathrm{~A}, \mathrm{U} 19>\mathrm{U} 16>\mathrm{U} 14$ \\
\hline Female & $37.36 \pm 5.22$ & $33.20 \pm 4.33$ & $32.35 \pm 3.96$ & $32.99 \pm 5.06$ & 3.9 & 0.06 & $\mathrm{~A}>\mathrm{U} 16, \mathrm{U} 14$ \\
\hline t-test & 5.945 & 5.629 & 4.543 & 0.440 & & & \\
\hline ES & 2.14 & 3.30 & 1.21 & 0.07 & & & \\
\hline \multicolumn{8}{|c|}{ Med. ball t. (m) } \\
\hline Male & $8.44 \pm 1.19$ & $6.92 \pm 1.24$ & $5.44 \pm 1.46$ & $3.45 \pm 0.70$ & 97.6 & 0.78 & $\mathrm{~A}>\mathrm{U} 19>\mathrm{U} 16>\mathrm{U} 14$ \\
\hline Female & $5.95 \pm 0.86$ & $5.73 \pm 0.43$ & $4.19 \pm 0.61$ & $3.07 \pm 0.58$ & 91.8 & 0.76 & $\mathrm{~A}, \mathrm{U} 19>\mathrm{U} 16>\mathrm{U} 14$ \\
\hline t-test & 7.267 & $2.263^{*}$ & 4.919 & 3.217 & & & \\
\hline ES & 2.40 & 1.30 & $X X X$ & 0.59 & & & \\
\hline \multicolumn{8}{|c|}{$\begin{array}{l}\text { Hand dyna. } \\
(\mathrm{N})\end{array}$} \\
\hline Male & $432.6 \pm 44.6$ & $388.5 \pm 69.1$ & $305.2 \pm 89.1$ & $192.9 \pm 47.1$ & 76.7 & 0.71 & $\mathrm{~A}, \mathrm{U} 19>\mathrm{U} 16>\mathrm{U} 14$ \\
\hline Female & $307.3 \pm 37.3$ & $241.4 \pm 23.8$ & $241.9 \pm 38.0$ & $175.8 \pm 30.8$ & 61.4 & 0.64 & $\mathrm{~A}>\mathrm{U} 19, \mathrm{U} 16>\mathrm{U} 14$ \\
\hline t-test & 9.535 & 3.658 & 3.835 & 2.256 & & & \\
\hline ES & 3.05 & 2.85 & 0.93 & 0.43 & & & \\
\hline \multicolumn{8}{|c|}{$20 \mathrm{~m}$ sprint (s) } \\
\hline Male & $3.04 \pm 0.13$ & $3.11 \pm 0.23$ & $3.25 \pm 0.27$ & $3.61 \pm 0.25$ & 37.7 & 0.53 & $\begin{array}{c}\mathrm{A}<\mathrm{U} 16, \mathrm{U} 14 ; \\
\mathrm{U} 19, \mathrm{U} 16<\mathrm{U} 14\end{array}$ \\
\hline Female & $3.46 \pm 0.21$ & $3.51 \pm 0.27$ & $3.53 \pm 0.20$ & $3.64 \pm 0.22$ & 3.3 & 0.11 & $\mathrm{~A}<\mathrm{U} 14$ \\
\hline t-test & -6.433 & -5.368 & -4.896 & -0.851 & & & \\
\hline ES & -2.41 & -1.59 & -1.18 & -0.13 & & & \\
\hline \multicolumn{8}{|l|}{ T test (s) } \\
\hline Male & $9.91 \pm 0.42$ & $10.38 \pm 0.49$ & $11.25 \pm 1.13$ & $12.23 \pm 1.00$ & 32.2 & 0.51 & $\mathrm{~A}, \mathrm{U} 19<\mathrm{U} 16<\mathrm{U} 14$ \\
\hline Female & $10.88 \pm 0.71$ & $11.27 \pm 0.59$ & $12.32 \pm 0.83$ & $12.72 \pm 0.99$ & 16.8 & 0.36 & $\begin{array}{c}\mathrm{A}<\mathrm{U} 16, \mathrm{U} 14 \\
\mathrm{U} 19<\mathrm{U} 14\end{array}$ \\
\hline t-test & -4.771 & -2.788 & -4.193 & -2.498 & & & \\
\hline ES & -1.66 & -1.67 & -1.08 & -0.49 & & & \\
\hline \multicolumn{8}{|l|}{$\begin{array}{l}\text { Yo-yo test } \\
(\mathrm{km} / \mathrm{h})\end{array}$} \\
\hline Male & $19.88 \pm 0.90$ & $17.16 \pm 2.27$ & $14.03 \pm 1.61$ & $13.33 \pm 1.21$ & 44.5 & 0.66 & $\mathrm{~A}>\mathrm{U} 19>\mathrm{U} 16, \mathrm{U} 14$ \\
\hline Female & $18.32 \pm 0.44$ & $18.60 \pm 0.71$ & $13.54 \pm 1.10$ & $13.08 \pm 0.88$ & 60.3 & 0.86 & A,U19>U16,U14 \\
\hline t-test & 0.395 & 2.190 & 2.174 & 0.672 & & & \\
\hline ES & 2.20 & -0.85 & 0.36 & 0.23 & & & \\
\hline
\end{tabular}

Med., Medicine; t., throwing; dyna., dynamometry; bold number, $p<0.05$ 
Table 3

Mean and standard deviation of each handball skills (throwing speeds and pass-to-wall test). A t-test was used to compare means between sexes in each group, and a one-way analysis of variance (ANOVA) with a Bonferroni post-hoc test was used to compare means between teams for each sex. Values of the effect sizes (ES) of the differences between the sexes (Cohen's $d$ ) and between teams (eta squared, $\left.\eta^{2}\right)$ (male, $n=115$; female, $n=111$ ) are provided.

\begin{tabular}{|c|c|c|c|c|c|c|c|}
\hline & $\begin{array}{l}\text { A Team } \\
(\mathrm{n}=29) \\
\mathrm{M} \pm \mathrm{SD}\end{array}$ & $\begin{array}{c}\mathrm{U} 19 \\
(\mathrm{n}=35) \\
\mathrm{M} \pm \mathrm{SD}\end{array}$ & $\begin{array}{c}\mathrm{U} 16 \\
(\mathrm{n}=73) \\
\mathrm{M} \pm \mathrm{SD}\end{array}$ & $\begin{array}{c}\mathrm{U} 14 \\
(\mathrm{n}=89) \\
\mathrm{M} \pm \mathrm{SD}\end{array}$ & $\mathrm{F}$ & $\eta^{2}$ & Differences \\
\hline \multicolumn{8}{|c|}{$\begin{array}{l}7 \mathrm{~m} \text { standing } \\
(\mathrm{km} / \mathrm{h})\end{array}$} \\
\hline Male & $82.57 \pm 6.34$ & $81.92 \pm 10.14$ & $73.80 \pm 10.94$ & $57.76 \pm 9.26$ & 42.8 & 0.57 & $\begin{array}{c}\mathrm{A}>\mathrm{U} 16>\mathrm{U} 14 ; \\
\mathrm{U} 19>\mathrm{U} 14\end{array}$ \\
\hline Female & $73.31 \pm 5.78$ & $64.20 \pm 2.05$ & $60.54 \pm 7.83$ & $48.47 \pm 7.82$ & 45.9 & 0.63 & $\begin{array}{c}\mathrm{A}>\mathrm{U} 16>\mathrm{U} 14 ; \\
\mathrm{U} 19>\mathrm{U} 14\end{array}$ \\
\hline t-test & 5.208 & 2.725 & 5.677 & 5.711 & & & \\
\hline ES & 1.53 & 2.42 & 1.39 & 1.18 & & & \\
\hline \multicolumn{8}{|c|}{$9 \mathrm{~m}$ after $\mathrm{s} .(\mathrm{km} / \mathrm{h})$} \\
\hline Male & $88.95 \pm 5.30$ & $84.54 \pm 11.22$ & $81.00 \pm 12.97$ & $60.51 \pm 9.02$ & 47.5 & 0.59 & $\begin{array}{c}\mathrm{A}>\mathrm{U} 16>\mathrm{U} 14 ; \\
\mathrm{U} 19>\mathrm{U} 14\end{array}$ \\
\hline Female & $78.46 \pm 5.56$ & $69.00 \pm 4.06$ & $64.50 \pm 8.04$ & $51.50 \pm 8.12$ & 50.3 & 0.67 & $\begin{array}{c}\mathrm{A}>\mathrm{U} 16>\mathrm{U} 14 ; \\
\mathrm{U} 19>\mathrm{U} 14\end{array}$ \\
\hline t-test & 5.973 & 2.252 & 6.143 & 5.777 & & & \\
\hline ES & 1.93 & 1.84 & 1.53 & 1.05 & & & \\
\hline \multicolumn{8}{|c|}{$\begin{array}{l}9 \mathrm{~m} \text { after s.j. } \\
(\mathrm{km} / \mathrm{h})\end{array}$} \\
\hline Male & $80.75 \pm 5.85$ & $77.46 \pm 7.92$ & $76.00 \pm 11.20$ & $60.90 \pm 9.41$ & 27.8 & 0.46 & A,U19,U16>U1 \\
\hline Female & $77.38 \pm 6.87$ & $72.40 \pm 2.30$ & $67.21 \pm 8.00$ & $56.48 \pm 7.47$ & 34.3 & 0.58 & $\begin{array}{c}\mathrm{A}>\mathrm{U} 16, \mathrm{U} 14 ; \\
\mathrm{U} 19>\mathrm{U} 14\end{array}$ \\
\hline t-test & 1.625 & 1.102 & 3.597 & 3.087 & & & \\
\hline ES & 0.53 & 0.87 & 0.90 & 0.52 & & & \\
\hline \multicolumn{8}{|c|}{ Pass to wall (r.) } \\
\hline Male & $24.86 \pm 3.62$ & $22.92 \pm 4.01$ & $19.16 \pm 5.30$ & $19.10 \pm 3.74$ & 11.0 & 0.25 & $\begin{array}{c}\text { A>U16,U14; } \\
\text { U19>U14 }\end{array}$ \\
\hline Female & $23.38 \pm 3.64$ & $20.00 \pm 6.44$ & $16.29 \pm 3.83$ & $15.14 \pm 3.62$ & 17.0 & 0.36 & $\mathrm{~A}>\mathrm{U} 16, \mathrm{U} 14$ \\
\hline t-test & 1.855 & 0.016 & 2.428 & 4.927 & & & \\
\hline ES & 0.41 & 0.54 & 0.62 & 1.08 & & & \\
\hline
\end{tabular}

s., steps; j., jump; r., repetition; bold number, $p<0.05$ 
Table 4

Discriminant analysis models for performance (starters vs. non-starters), giving the percentage correctly classified, Wilks's lambda, canonical correlation index, and variables included in the model by order of selection.

\begin{tabular}{|c|c|c|c|c|}
\hline & A Team & U19 & U16 & $\mathrm{U} 14$ \\
\hline \multicolumn{5}{|l|}{ Males } \\
\hline $\begin{array}{l}\text { Percentage correctly } \\
\text { classified }\end{array}$ & $80.0 \%$ & $61.5 \%$ & $77.4 \%$ & $100 \%$ \\
\hline Wilks's lambda & 0.013 & 0.373 & 0.724 & 0.220 \\
\hline $\begin{array}{l}\text { Canonical correlation } \\
\text { index }\end{array}$ & 0.994 & 0.792 & 0.525 & 0.883 \\
\hline Variables selected & $\begin{array}{c}\text { BMI } \\
\text { Yo-yo IR2 test } \\
\text { T test }\end{array}$ & Pass to wall & $\mathrm{T}$ test & $\begin{array}{l}\text { Yo-yo IR2 test } \\
\text { Arm span }\end{array}$ \\
\hline \multicolumn{5}{|l|}{ Females } \\
\hline $\begin{array}{l}\text { Percentage correctly } \\
\text { classified }\end{array}$ & $100 \%$ & $75.0 \%$ & $48.5 \%$ & $72.1 \%$ \\
\hline Wilks's lambda & 0.002 & 0.003 & 0.721 & 0.541 \\
\hline $\begin{array}{l}\text { Canonical correlation } \\
\text { index }\end{array}$ & 0.999 & 0.999 & 0.528 & 0.677 \\
\hline Variables selected & $\begin{array}{c}9 \mathrm{~m} \text { after steps } \\
\text { Hand dynamometry } \\
9 \mathrm{~m} \text { after steps \& jump } \\
\text { Arm span } \\
\text { Hand length } \\
\text { Yo-yo IR2 test }\end{array}$ & $\begin{array}{c}9 \text { m after steps } \\
\text { Body mass } \\
\text { Medicine ball } \\
\text { throw }\end{array}$ & Body mass & $\begin{array}{c}9 \mathrm{~m} \text { after steps \& } \\
\text { jump }\end{array}$ \\
\hline
\end{tabular}

With respect to the age differences in physical condition, our results do not concur with those of previous studies which only found differences in $10 \mathrm{~m}$ and $30 \mathrm{~m}$ sprints and the SJ (Ingebrigtsen et al., 2013) or the CMJ (Saavedra et al., 2018). Likewise, growing and maturation appear to influence the variables studied (Pearson et al., 2006) since the lowest values corresponded to the U14 teams. Previous longitudinal studies of male handball players, but with smaller samples than those of the present study (Matthys et al.,
2012, 2013) have shown an increase in conditioning abilities from 12 to 14 years in age. On the other hand, the absence of differences between the U19 and A teams might suggest that more specialized training is necessary in adulthood. With regard to handball skills, our results do not concur with those of previous studies of male players in the Spanish (OrtegaBecerra et al., 2018) and Norwegian (Shalfawi et al., 2014) leagues which found differences between the groups in the jump-throw and 3- 
steps throwing speeds. They do, however, coincide with those of a previous study of elite players (Saavedra et al., 2018).

With regard to the differences according to sex, our results are consistent with a study of elite adult handball players which found differences between the sexes (adult elite men and women players) in $15 \mathrm{~m}$ and $30 \mathrm{~m}$ sprints, the CMJ, and throwing speed (Wagner et al., 2018). The results of a study of the Brazilian Olympic teams (Pereira et al., 2018) were in the same line, finding differences in $10 \mathrm{~m}$ and $20 \mathrm{~m}$ sprints, the $\mathrm{CMJ}$, and the zig-zag and $\mathrm{T}$ tests. For the U14 teams, however, fewer variables differentiated the sexes. This may be because peak height velocity occurs earlier in females than in males (IulianoBurns et al., 2001). The present results do not agree with those of a study of 14-year-old Brazilian players which found differences between the sexes in body height and mass, horizontal jump, agility and abdominal tests (Dellagrana et al., 2010). This disagreement is perhaps due to the geographical differences in the two samples (Iceland vs. Brazil)

Considering now the eight multivariate models that were constructed (to model the performance level differences), we observed that in males, the variables most selected by the models (twice each) were the yo-yo IR2 test and the $\mathrm{T}$ test. That the yo-yo IR2 test (aerobicanaerobic performance) and $\mathrm{T}$ test (agility) were selected is at least in part coincident with previous studies (Lidor et al., 2005; Matthys et al., 2011) which used different tests, but of which models also selected aerobic-anaerobic performance and agility. Thus, in the study carried out with players aged from 12 to 16 (Lidor et al., 2005), the variables selected by the model to predict whether or not they belonged to the national team were the medicine ball throw, long jump, slalom test (agility), and $4 \times 10 \mathrm{~m}$ shuttle run test. In the more recent of those two studies (Matthys et al., 2011), the variables selected by the models to discriminate between elite and non-elite male players were: in U14, the slalom dribble test (agility) and the $5 \mathrm{~m}$ sprint; in U16, the slalom dribble test (agility), hand dynamometry and the yo-yo IR1 test (aerobic-anaerobic performance); and in U18, the five-jump test and the sit-andreach test. It is noteworthy that no model selected any variable related to throwing speed. This may have been due to the common characteristics of the sample analysed, since differences in throwing speed have been found in comparing elite with non-elite or professional adult players (Gorostiaga et al., 2005) or semi-professionals with amateurs (Rivilla-García et al., 2011). In women, the variables selected by the multivariate models did not coincide with a study of elite players in which the $7 \mathrm{~m}$ standing throwing speed was the only variable selected (Saavedra et al., 2018). Variables related to throwing speed (with and without the jump, with and without opposition) have, however, been found to differ between top-elite and elite players (Ferragut et al., 2018). Although our different models selected more than one conditioning variable, similar models in another study (Lidor et al., 2005) of 12- and 16-year-old players only selected the medicine ball throw. That the models selected different variables is consistent with two longitudinal studies (Lidor et al., 2005; Matthys et al., 2013) of male players in which the variables selected were found to change with the age of the subjects.

The present study has several limitations. Firstly, since this was a cross-sectional study, comparisons based on age should be taken with caution. Nonetheless, the data do point along the same line as those of the two longitudinal studies that have been carried out to date (Lidor et al., 2005; Matthys et al., 2013). Secondly, there is the absence of data concerning the physical (biological) maturity or body composition of the players. These are evaluations that ought to be taken into account for players younger than 18 (Pearson et al., 2006). Unfortunately, it was not possible to do so in the present study since the evaluations were carried our during the players' training hours, and the time available was limited. Thirdly, performance was taken to be represented by the dichotomy of a starter or a non-starter, so that the players' specific positions were not considered even though they may have influenced the variables studied (Karcher and Buchheit, 2014).

\section{Conclusions}

In summary, the study has shown that differences between the U19 and A teams were in almost all the variables, and that the lowest values corresponded to U14. This seems to indicate that, in case of the A team, there is a need for more specific training. While there were clear 
differences by sex, this was not the case for all the handball skills between the U19 and A teams, suggesting that, by adulthood, technical actions do not differ much between male and female players. Finally, the multivariate models successfully predicted performance at high percentages (above $72 \%$ in six of the eight models). Conditioning variables were most discriminating in men, and handball skills in women. This seems to reflect the different performance profiles which are present in match play of male and female handball players (Michalsik and Aagaard, 2015).

\section{Acknowledgements}

We would like to acknowledge the collaboration of Handknattleiksfélag Kópavogs (HK Club). The authors wish to thank Robert A. Chatwin PhD for revision of the English and every one of the participants in the study. Also, we like to thanks BSc students that collaborated in data collection, Philipp Behncke (especially), Andri Hjartar Grétarsson, Garðar Ó. Ágústsson, Fanney Rós Magnúsdóttir.

\section{References}

Balsalobre-Fernández C, Tejero-González CM, del Campo-Vecino J, Bavaresco N. The concurrent validity and reliability of a low-cost, high-speed camera-based method for measuring the flight time of vertical jumps. J Strength Cond Res, 2014; 28: 528-533

Bangsbo J, Iaia FM, Krustrup P. The Yo-Yo intermittent recovery test: a useful tool for evaluation of physical performance in intermittent sports. Sports Med, 2008; 38: 37-51

Bosco C, Luhtanen P, Komi PV. A simple method for measurement of mechanical power in jumping. Eur J Appl Physiol, 1983; 50: 273-282

Cohen J. Statistical power analysis for the behavioral sciences (2nd ed.). Hillsdale, NJ: Erlbaum Associates; 1988

Council of Europe. Eurofit: Handbook for the EUROFIT test of physical fitness. Rome: Secretariat of the Committee for Development of Sport within the Council of Europe; 1988

Dellagrana RA, Silva MP, Smolarek AC, Bozza R, Neto AS, Campos W. Body composition, sexual maturation and motor performance the young practitioners handball. Motriz: Rev Educ Fis, 2010; 16: 880-888

Ferragut C, Vila H, Abraldes JA, Manchado C. Influence of physical aspects and throwing velocity in opposition situations in top-elite and elite female handball players. J Hum Kinet, 2018; 63: 23-32

Ghobadi H, Rajabi H, Farzad B, Bayati M, Jeffreys I. Anthropometry of world-class elite handball players according to the playing position: Reports from Men's Handball World Championship 2013. J Hum Kinet, 2013; 39: 213-220

Gorostiaga EM, Granados C, Ibanez J, Izquierdo M. Differences in physical fitness and throwing velocity between elite and amateur male handball players. Int J Sports Med, 2005; 26: 225-532

Hopkins WG, Marshall SW, Batterham AM, Hanin, J. Progressive statistics for studies in sports medicine and exercise science. Med Sci Sports Exerc, 2009; 41:3-13

Ingebrigtsen J, Jeffreys I, Rodahl S. Physical characteristics and abilities of junior elite male and female handball players. J Strength Cond Res, 2013; 27: 302-309

ISAK. International standards for anthropometric assessment. Wellington (New Zealand): Lower Hutt; 2011

Iuliano-Burns S, Mirwald RL, Bailey DA. Timing and magnitude of peak height velocity and peak tissue velocities for early, average, and late maturing boys and girls. Am J Hum Biol, 2001; 13: 1-8

Karcher C, Buchheit M. On-court demands of elite handball, with special reference to playing positions. Sports Medicine, 2014; 44: 797-814

Keys A, Brozek J. Body fat in adult man. Physiol Rev, 1953; 33: 245-325

Krüger K, Pilat C, Uckert K, Frech T, Mooren FC. Physical performance profile of handball players is related to playing position and playing class. J Strength Cond Res, 2014; 28: 117-125

Krustrup P, Mohr M, Nybo L, Jensen JM, Nielsen JJ, Bangsbo J. The Yo-Yo IR2 test: physiological response, reliability, and application to elite soccer. Med Sci Sports Exerc, 2006; 38: 1666-1673

Lidor R, Falk B, Arnon M, Cohen Y, Segal G, Lander, Y. Measurement of talent in team handball: the questionable use of motor and physical tests. J Strength Cond Res, 2005; 19: 318-325 
Matthys SPJ, Vaeyens R, Fransen J, Deprez D, Pion J, Vandendriessche J, Vandorpe B, Lenoir M, Philippaerts R. A longitudinal study of multidimensional performance characteristics related to physical capacities in youth handball. J Sports Sci, 2013; 31: 325-334

Matthys SP, Vaeyens R, Coelho-e-Silva M, Lenoir M, Philippaerts R. The contribution of growth and maturation in the functional capacity and skill performance of male adolescent handball players. Int $J$ Sports Med, 2012; 33: 543-549

Michalsik LB, Aagaard P. Physical demands in elite team handball: Comparisons between male and female players. J Sports Med Phys Fitness, 2015; 55: 878-891

Ortega-Becerra M, Pareja-Blanco F, Jiménez-Reyes P, Cuadrado-Peñafiel V, González-Badillo JJ. Determinant factors of physical performance and specific throwing in handball players of different ages. J Strength Cond Res, 2018; 32: 1778-1786

Pearson DT, Naughton GA, Torode M. Predictability of physiological testing and the role of maturation in talent identification for adolescent team sports. J Sci Med Sport, 2006; 9: 277-287

Pereira LA, Nimphius S, Kobal R, Kitamura K, Turisco LAL, Orsi RC, Cal Abad CC, Loturco I. Relationship between change of direction, speed, and power in male and female national Olympic team handball athletes. J Strength Cond Res, 2018; 32: 2987-2994

Rivilla-García J, Grande I, Chirosa LJ, Gómez MJ, Sampedro J. Differences and relationship between standard and specific throwing test in handball according to the competitive and professional level. J Sport Health Res, 2010; 3: 143-52

Rivilla-Garcia J, Grande I, Sampedro J, van den Tillaar R. Influence of opposition on ball velocity in the handball jump throw. J Sports Sci Med, 2011; 10: 534-539

Saavedra JM. Handball research: State of the art. J Hum Kinetics, 2018; 63: 5-8

Saavedra JM, Kristjánsdóttir H, Einarsson IP, Guðmundsdóttir ML, porgeirsson S, Stefansson A. Anthropometric characteristics, physical fitness, and throwing speed in elite women's handball teams. J Strength Cond Res, 2018; 32: 2294-2301

Semenick D. Test and measurements: The T- test. Nat Strength Cond Assoc J, 1990; 12: 36-37

Shalfawi SAI, Seiler S, Tønnessen E, Haugen TA. Aspect of shooting velocity in Norwegian elite team handball. Serbian J Sports Sci, 2014; 8: 33-40

Vila H, Manchado C, Rodriguez N, Abraldes JA, Alcaraz P, Ferragut, C. Anthopometric profile, vertical jump, and throwing velocity in elite female handball players by positions. J Strength Cond Res, 2012; 26: $2146-2155$

Visnapuu, M., Jürimäe, T. The influence of basic body and hand anthropometry on the results of different throwing tests in young handball and basketball players. Anthropol Anz, 2008; 66: 225-236

Wagner H, Finkenzeller T, Würth S, von Duvillard SP. Individual and team performance in team-handball: A review. J Sports Sci Med, 2014; 13: 808-816

Wagner H, Fuchs P, Fusco A, Fuchs P, Bell WJ, Duvillard SP. Physical performance in elite male and female team handball players. Int J Sports Physiol Perform, 2018; 12: 1-24

Weber J, Wegner M. Constitutional demands for different playing positions in female team handball. Sportwissenschaft, 2016; 46: 305-314

Zapartidis, I, Vareltzis, I, Gouvali, M, and Kororos, P. Physical fitness and anthropometric characteristics in different levels of young team handball players. Open Sports Sci J, 2009; 2: 22-28

\section{Corresponding author:}

\section{Jose M. Saavedra}

Physical Activity, Physical Education, Health and Sport Research Centre (PAPESH).

School of Science and Engineering. Reykjavik University.

Menntavegur 1, Nauthólsvík, 101 Reykjavík, Iceland.

Phone: +354 599 6200. Fax + 3545996201

Email: saavedra@ru.is 